\title{
Etiology of Neonatal Convulsions and Anticonvulsant Drugs
}

\author{
Duygu Besnili Acar (10, Ali Bülbül (1), Sinan Uslu (D), Ilkay Özmeral Odabaşı (D), Bülent Güzel (1) \\ Department of Neonatology, University of Health Sciences Şişli Hamidiye Etfal Training and Research Hospital, İstanbul, Turkey
}

Cite this article as: Besnili Acar D, Bülbül A, Uslu S, Özmeral Odabaşı I, Güzel B. Etiology of Neonatal Convulsions and Anticonvulsant Drugs. JAREM 2019; 9(1): 1-5.

\begin{abstract}
Objective: The aim of our study was to evaluate the etiology and type of seizures in newborns, and to compare the efficacy of various anticonvulsant drugs.

Methods: Patients hospitalized at the Level 3 neonatal intensive care unit between December 2010 and January 2015 and diagnosed with seizures were included in the study. Obtained data were compared with regard to the term and preterm subgroups. Definition analysis, Pearson's chi-squared test, and independent t-test were used as statistical methods.

Results: Forty-one out of 1322 patients hospitalized at the Level 3 neonatal intensive care unit were diagnosed with seizures. Considering gender, $63.4 \%$ were male, and $80 \%$ of the patients were full term. The mean birthweight was 3066 grams, and the average delivery was at 37.9 weeks. The most common etiologic factors were hypoglycemia (14.6\%), hypoxic ischemic encephalopathy (12.2\%), and hypocalcemia (12.2\%). Convulsion types were the following: unclassified type (29.3\%), focal tonic (26.8\%), myoclonic (19.5\%), autonomic (19.5\%), and focal clonic (17.1\%). Phenobarbital was used as a first-choice drug in $82.6 \%$ of patients. A secondary anticonvulsant drug was required in $30 \%$ patients, and phenytoin was used in $71.4 \%$ patients. Comparing the data of the full term and preterm subgroups, the seizure etiology, type of convulsion, convulsion time, and medications used to control the seizure were not different. However, preterm patients did not require a secondary antiepileptic drug, as opposed to term patients.

Conclusion: Our study demonstrated that the most common disorders that cause seizures in newborns are hypoglycemia, hypoxic ischemic encephalopathy, and hypocalcemia, and one half of the patients did not require any anticonvulsant drug. When a secondary drug was required, it was usually phenobarbital. Preterm newborns usually did not require secondary drugs.
\end{abstract}

Keywords: Anticonvulsant drug, convulsion, newborn

\section{INTRODUCTION}

Convulsions are a temporary neurological function disorder occurring as a result of paroxysmal discharge of a group of neurons. Since the central nervous system (CNS) maturation in newborns is not fully established, newborns are more prone to convulsions, and the clinical features of the convulsions differ from those during childhood. The frequency of convulsions in newborns ranges between 1.8 and 3.5 in 1000 live births (1). During the newborn period, hypoxic ischemic encephalopathy (HIE), intracranial bleeding, CNS infections, acute metabolic impairments, congenital metabolic impairments, congenital malformations in the CNS, cerebrovascular events, medications, and newborn's benign convulsions play a role in the convulsion etiology (2-4).

Today, there is no agreement on the methodology of the newborn convulsion diagnosis. The main reason for this is consid- ered to be the incomplete maturation of the CNS. During the neonatal period, while axonal and dendritic formations are complete, synaptic connections are not, and generalized tonic-clonic convulsions cannot be observed. Studies have shown that EEG cannot detect pathological findings in two-thirds of babies with suspicious convulsions, and the electrical activity has been associated with incomplete electrical activity myelination (2). In contrast, when babies in the risk group were followed by a routine EEG, one-third of babies without the signs of clinical features had the convulsion activity in EEG (5). Today, the necessity of the copresence of clinical findings and EEG findings for the convulsion diagnosis in newborns is mainly accepted (6).

There is no standard treatment methodology for newborn convulsion described in the literature. In the treatment, phenobarbital, levetiracetam, phenytoin, lorazepam, and diazepam are used (6).

ORCID IDs of the authors: D.B.A. 0000-0002-3623-2618; A.B. 0000-0002-3510-3056; S.U. 0000-0002-2004-0419; i.Ö.0. 0000-0002-7717-4426; B.G. 00000002-8485-5422. 
Our study compared the demographic properties, clinical features, convulsion etiologies, treatment methodologies, and short-term results of patients hospitalized in the newborn intensive care unit to those found in the literature.

\section{METHODS}

The files of the third-stage newborn intensive care unit patients diagnosed with convulsions between January 2010 and December 2015 (6 years) were analyzed retrospectively. The Ethic Committee's approval (1167/05/01/2016) was obtained. Patient consent could not be obtained since the study was established, retrospectively. Mothers' and babies' prenatal, natal, and postnatal demographic findings, convulsion etiologies, convulsion types, anticonvulsant therapy types, imaging results, and aEEG findings were recorded in the study form.

\section{Definitions}

Hypoxic Ischemic Encephalopathy: Cerebral harm occurring in many organs and tissues, especially the CNS, as a result of asphyxiated process. The Sarnat and Sarnat scoring is used for identification (7).

Hypoglycemia: A serum glucose level $<40 \mathrm{mg} / \mathrm{dL}$ in babies with the syndrome

Hypocalcemia: The serum calcium level of $8 \mathrm{mg} / \mathrm{dL}$ and $<7 \mathrm{mg} /$ $\mathrm{dL}$ in term and preterm babies, respectively

Infection: For the CNS infection diagnosis, pathogenic bacteria should reproduce in the BOS culture or patient's serum infection criteria (CRP, procalcitonin, number of leukocytes) increase should be accompanied with lumbar puncture results (leukocyte level $\geq 10 / \mathrm{mm}^{3}$ and protein increase) in favor of meningitis.

CNS Abnormality: Diagnosis is made upon cranial ultrasonography, computerized tomography, and/or magnetic resonance imaging results in babies.

\section{Statistical Analysis}

For statistical analysis, the descriptive statistic method was used for the evaluation of demographic features. Comparison of data was obtained by the Parson chi-squared test. The term and preterm babies' data were compared using the independent t-test. A p-value $<0.05$ was accepted as statistically significant.

\section{RESULTS}

Between 2010 and 2015 in our clinic, the number of live births was 21.578 , the number of the third-stage hospitalized babies was 1322 , the number of babies with convulsions was 41 , and the convulsion rate was $1.9 \%$ in 1000 live births and $3.1 \%$ in the thirdstage hospitalized babies. The gender distribution of the babies was 26 boys (63.4\%) and 15 girls (36.6\%). The average birth weight of the cases was $3066 \mathrm{~g}$ (the lower-upper limit). A total of $80 \%$ of babies were term, while $20 \%$ were preterm. The demographic features of the babies are shown in Table 1 in detail. The first- and fifth-minute APGAR scores were 6 and 9, respectively. When the maternal features were analyzed, the average age of mothers was 29.2 years (lower-upper limit: 20-38 years). While
$73.1 \%$ of the mothers were healthy, $26.9 \%$ had chronic diseases (3 diabetes, 5 hypothyroid, 3 epilepsy). When babies' family trees were analyzed, $9.8 \%(n=4)$ were from consanguineous families, and $22 \%(n=9)$ had a history of convulsion.

Three out of five babies subjected to active hypothermia due to perinatal asphyxia and followed by an aEEG had burst suppression findings in aEEG; no pathology was detected in the remaining 2.

The most frequent convulsion type observed in babies was the subtle type with 29.3\% ( $n=12)$ (Table 2). The most frequent etiology factor was hypoglycemia with $14.6 \%(n=6)$ (Table 3$)$.

The evaluation of the occurrence of convulsion showed that $63.4 \%$ of babies had convulsions within the first week of their life, $36.6 \%$ had them after the first week, and they were brought to hospital on the $5^{\text {th }}$ day on average (first-third quarter: 2-10 days).

During the follow-up, 18 (43.9\%) babies did not have convulsions again and an anticonvulsant drug was not used since the therapy was applied for the underlying cause. Babies who were not given anticonvulsant drugs were treated according to their etiological causes. Twenty-three babies with convulsions were subjected to anticonvulsant therapy. Phenobarbital was chosen as the initial treatment option in $82 \%$ of cases, while treatment was initiated in $9 \%$ both with levetiracetam and phenytoin.

Among the babies who underwent treatment, $30 \%$ required the second anticonvulsant drug application. When the diagnoses of these babies were analyzed, cerebral infarct, holoprosencephaly, hydrocephalus secondary to intraventricular hemorrhage, periventricular leukomalacia, and subependymal hemorrhage were observed in 1 baby; no any other etiology was detected in 2 babies (Table 4).

In our study, when the data of term and preterm babies were compared, a significant difference was not detected with regard to the convulsion etiology, type, number, the time of occurrence of the convulsion, and used antiepileptic drugs. Unlike term babies, secondary antiepileptic treatment was not necessary in preterm babies.

\section{Table 1. Demographic features}

\begin{tabular}{|l|c|}
\hline Gender & \\
\hline Male & $63.4 \%$ \\
\hline Female & $36.6 \%$ \\
\hline Time of convulsion, day ${ }^{\alpha}$ & $5(1-27)$ \\
\hline Birth weight, gram ${ }^{\alpha}$ & $3066(850-4500)$ \\
\hline Time of birth, week $^{\alpha}$ & $37.9(25-41)$ \\
\hline Mother's age, year ${ }^{\alpha}$ & $29.2(20-38)$ \\
\hline Frequency of consanguinity & $9.8 \%$ \\
\hline Family history on convulsion & $22 \%$ \\
\hline${ }^{\alpha}$ Values are given as average (lower-upper limit) & \\
\hline
\end{tabular}




\section{DISCUSSION}

Convulsions in newborn babies are an important cause of morbidity and mortality. The convulsion frequency during the neonatal period is 1-3.5 in 1000 live births (8). Similarly, in our study, the convulsion frequency in newborns was found to be 1.9 in 1000 live births. Convulsion frequencies for babies hospitalized in newborn intensive care units have been reported at quite different rates. The main reason for different rates is contributed to the subjective decision of convulsion diagnosis and diagnosing according to clinical findings. In our study, the frequency of convulsions in the third-stage patients hospitalized at newborn intensive care units has been detected as 3.1\%. Sabzehei et al. (9) and Moayedi et al. (10) reported the frequency of convulsions as $9.1 \%$ and $2.5 \%$, respectively.

The male gender, C-section birth, mother's age $<18$ or $>40$ years, maternal diabetes, maternal infection, fetal distress, and preterm

\section{Table 2. Convulsion types}

\begin{tabular}{|l|c|}
\hline Convulsion types & $\mathbf{n}(\%)$ \\
\hline Subtle & 29.3 \\
\hline Focal clonic & 17.1 \\
\hline Focal tonic & 26.8 \\
\hline Myoclonic & 19.5 \\
\hline Autonomic & 19.5 \\
\hline
\end{tabular}

Table 3. Etiological reasons

\begin{tabular}{|l|c|}
\hline Hypoglycemia & $14.6 \%$ \\
\hline Hypocalcemia & $12.2 \%$ \\
\hline HIE & $12.2 \%$ \\
\hline Cerebral abnormality & $7.3 \%$ \\
\hline Metabolic disease & $7.3 \%$ \\
\hline Sepsis & $4.8 \%$ \\
\hline IVH & $2.4 \%$ \\
\hline Unidentified & $16 \%$ \\
\hline HIE: hypoxic ischemic encephalopathy; IVH: intraventricular hemorrhage
\end{tabular}

Table 4. Anticonvulsant treatment options

\begin{tabular}{|l|c|c|}
\hline Drugs & $\begin{array}{c}\text { First Choice as an } \\
\text { Anticonvulsant Drug }\end{array}$ & $\begin{array}{c}\text { Drugs Used in Case of } \\
\text { Necessity as Secondary } \\
\text { Anticonvulsant } \\
\text { Drugs }\end{array}$ \\
\hline Phenobarbital & $19(82.6 \%)$ & 0 \\
\hline Phenytoin & $2(8.6 \%)$ & $5(71.4 \%)$ \\
\hline Levetiracetam & $2(8.6 \%)$ & $1(14.2 \%)$ \\
\hline Midazolam & 0 & $1(14.2 \%)$ \\
\hline
\end{tabular}

birth are risk factors in neonatal convulsions (11-13). In our study, while the male gender and C-section were observed at higher rates, unlike other studies, we did not have any cases carrying risk in terms of mother's age.

A point raising attention in our study is the presence of a family history of convulsions in $22 \%$ of our cases. This is indirectly indicative of the involvement of genetic factors in the evaluation of convulsion etiology in babies. In the literature, many mutations have been reported in familial transition in convulsion and epileptic patients. The most frequently observed mutation is reported as KCNQ2 (14). However, the relation between these mutations and convulsions observed during the neonatal period is not definitely known. We believe that genetic analysis planning can play a part in diagnosis in case of the convulsion presence in the family history of newborn babies with an unidentified etiology.

The most frequently detected type of convulsions during the neonatal period was the subtle type in studies $(10,15)$. The subtle type is reported to be mainly followed by tonic convulsions. The finding that the most frequent type is the subtle one in our study is also supported in other studies.

While the distribution of etiological reasons for newborn convulsions show differences, hypoxic ischemic encephalopathy is accepted to be the most frequent reason. In their study, Moayedi et al. (10) and Arpino et al. (16) reported hypoxic ischemic encephalopathy as the most frequent reason. On the other hand, Taksande et al. stated that infections were in the first place with $28.2 \%$ (17). In a recent prospective and comprehensive study including 426 babies, the etiological reasons for newborn convulsions were $\mathrm{HIE}$ at $38 \%$, ischemic attack $18 \%$, intracranial hemorrhage $12 \%$, genetic epilepsy $6 \%$, intracranial hemorrhage $4 \%$, hypoglycemia and/or electrolyte impairments $4 \%$, metabolic diseases 3\%, benign familial epilepsy $3 \%$, and unidentified $9 \%(6)$. The etiological evaluation in our study revealed different results than those in the literature; hypoglycemia was in the first place with $14.6 \%$, and the second most frequent were hypoxic ischemic encephalopathy and hypocalcemia with $12.2 \%$. It is known that the country development level and regional geographic properties are also effective in an important ratio and change etiologic ranking in convulsion during the neonatal period.

In their study, Glass et al. (6) reported the frequency of the CNS infections in convulsion etiology as $4 \%$. The CNS infections and sepsis were detected in $4.8 \%$ in our patient cohort, but studies in developing countries reported the presence of sepsis between $17.2 \%-28.7 \%$ in etiology $(9,17)$.

In our study, the frequency of intraventricular bleeding in the convulsion etiology was detected at $2.4 \%$. While this ratio is approximately $6.9 \%$ in the studies by Malik et al. (18) and Sabzehei et al. (9), Ross et al. (19) and Glass et al. (6) detected higher ratios. We believe that the reason for a lower ratio in our study can be explained by a higher birth weight of babies in our study cohort.

Phenobarbital is preferred as the first choice medication in the treatment of neonatal convulsions, and when there is a need for a second medication, phenytoin is usually added. In the study 
by Painter Mu et al. (20), out of a total of 59 babies; 13 out of 30 babies (43\%) showed responded to phenobarbital, 13 of 29 (45\%) responded to phenytoin, and in 15 patients who had no reaction to phenobarbital, phenytoin was added as a second medication; only 4 of these patients responded.

Glass et al. (6) stated that they used phenobarbital at the first stage in $94 \%$ of babies, and their second choice were levetiracetam and phosphenytoin. In recent years, it has been shown that levetiracetam might be an appropriate treatment approach in patients with cardiac and liver dysfunction, and it has been used in the second stage of treatment because of its neuroprotective effect and because it shows no neuronal apoptosis properties (21). In 37 preterm babies, levetiracetam was used as an anticonvulsant at the first stage safely without developing any side effects, but it has been emphasized that a double-blind and randomized study including more cases should be performed (22). In our country, there is a problem in obtaining intravenous form of phenobarbital, and when not supplied, phosphenytoin and levetiracetam are used.

In our study, phenytoin and levetiracetam were used as primary drugs in 4 babies because phenobarbital could not be obtained.

It has been reported that there is an underlying persistent convulsion etiology, mostly HIE, stroke and intracranial bleeding in therapy-resistant cases (6). In our study, 7 babies receiving anticonvulsant therapy needed secondary antiepileptic therapy due to their resistance to therapy, and these babies' diagnoses were congenital CNS abnormalities, periventricular leukomalacia, stroke, and congenital metabolic disease.

There is no accepted protocol at the international level regarding the diagnosis and therapy of convulsion during the neonatal period. An aEEG evaluation together with clinical findings is suggested, but there are a lot of problems regarding indications of an aEEG application and the availability in developing countries. While phenobarbital is the most frequently used drug in neonatal convulsion therapy, the widespread use of levetiracetam is increasing. Regardless of the anticonvulsant therapy applied, almost half of the neonatal convulsion cases require the use of a secondary anticonvulsant.

\section{CONCLUSION}

This study showed that hypoglycemia, HIE, and hypocalcemia are among the most frequent reasons for convulsions in newborns, and almost one half of the babies does not require anticonvulsant therapy. Phenobarbital is the most preferred primary medication, and preterm babies do not need secondary anticonvulsant drugs. Babies with neonatal convulsions had a significant family history regarding convulsions. In the future, it is predicted that an analysis of genetic factors will be important in the evaluation of the convulsion etiology in newborns with convulsions due to an unidentified reason.

Ethics Committee Approval: Ethics committee approval was received for this study from the Ethics Committee of Şişli Hamidiye Etfal Training and Research Hospital (Approval date: 05/01/2016, number: 1167).
Informed Consent: Informed consent was not taken from patients due to the retrospective nature of the study.

Peer-review: Externally peer-reviewed.

Author Contributions: Concept - D.B.A., A.B.; Design - S.U.; Supervision - I.Ö.O.; Resources - B.G., S.U.; Data Collection and/or Processing - B.G.; Analysis and/or Interpretation - I.Ö.O.; Literature Search - D.B.A.; Writing Manuscript - A.B., D.B.A.; Critical Review - S.U., B.G., I.Ö.O.

Conflict of Interest: The authors have no conflict of interest to declare.

Financial Disclosure: The authors declared that this study has received no financial support.

\section{REFERENCES}

1. Chapman EK, Raol HY, Brooks-Kayal A. Neonatal seizures: controversies and challeges in translating new therapies from the lab to the isoletta. Eur J Neurosci 2012; 35: 1857-65. [CrossRef]

2. Volpe JJ. Neonatal seizures. In: Neurology of the newborn. Philadelphia: WB Saunders 2008; 203-37.

3. Estan J, Hope P. Unilateral neonatal cerebral infarction in full term infants. Arch Dis Child Fetal Neonatal Ed 1997; 76: 88-93. [CrossRef]

4. Levene MI, Trounce JQ. Cause of neonatal convulsions. Arch Dis Child 1986; 61: 78-9. [CrossRef]

5. Murray DM, Boylan GB, Ali I, Ryan CA, Murphy BP, Connolly SO. Defining the gap between electrographic seizure burden, clinical expression and staff recognition of neonatal seizures. Arch Dis Child Fetal Neonatal Ed 2008; 93: 187-91. [CrossRef]

6. Glass HC, Shellhaas RA, Wusthoff CJ, Chang T, Abend NS, Chu CJ, et al. Contemporary Profile of Seizures In Neonates: A Prospective Cohort Study. J Pediatr 2016; 174: 98-103. [CrossRef]

7. Sarnat, HB, Sarnat, M.S. Neonatal encephalopathy following fetal distress: A clinical and electroencephalographic study. Arch Neurol Chicago 1976; 33: 696-705. [CrossRef]

8. Glass HC, Wirrell E. Controversies in Neonatal Seizure Management. J Child Neurol 2009; 24: 591-9. [CrossRef]

9. Sabzehei MK, Basiri S, Bazmamoun H. The Etiology, Clinical Type, and Short Outcome of Seizures in Newborns Hospitalized in Besat Hospital/Hamadan/ Iran. Iran J Child Neurol 2014; 8: 24-8.

10. Moayedi AR, Zakeri S, Moayedi F. Neonatal seizures: Etiology and type. Iran J child Neurol 2007; 23.

11. Saliba R, Annegars FJ, Waller DK, Tyson JE, Mizrahi EM. Incidence of neonatal seizures in Haris County, Texas, 1992-1994. Am J Epidemiol 1999; 150: 763-9. [CrossRef]

12. Ronen GM, Penney S, Andrews W. The epidemiology of clinical neonatal seizures in Newfoundland: a population-based study. J Pediatr 1999; 134: 71-5. [CrossRef]

13. Glass HC, Pham TN, Danielsen B, Towner D, Glidden D, Wu YW. Antenatal and intrapartum risk factors for seizures in term newborns: a population-based study, California 1998-2002. J Pediatr 2009; 154: 24-8. [CrossRef]

14. Shellhaas RA, Wusthoff CJ, Tsuchida TN, Glass HC2, Chu CJ2, Massey $\mathrm{SL}$, et al. Profile of neonatal epilepsies: Characteristics of a prospective US cohort. Neurology 2017; 89: 893-9. [CrossRef]

15. Tekgul H, Gauvrea K, Soul J, Murphy L, Robertson R, Stewart J, et al. The current etiology profile and neurodevelopmental outcome of seizures in term newborn infants. Pediatrics 2006; 117: 1270-80. [CrossRef]

16. Arpino C, Domizio S, Carrieri MP, Brescianini DS, Sabatino MH, Curatolo P. Prenatal and perinatal determinants of neonatal seizures occurring in first week of life. Abs J child Neurol 2001; 16: 651-6. [CrossRef] 
17. Taksande A, Vilhecar K, Jain M, Lakra M. Clinico- Biochemical Profile of Neonatal Seizures. Indian J Pediatr 1995; 52: 424-7.

18. Malik BA, Butt MA, Shamoon M, Tehseen Z, Fatima A, Hashmat N. Seizures etiology in the newborn period. J Coll Physicians Surg Pak 2005; 15: 786-90.

19. Ross AL, Lombroso CT. Neonatal seizures state. A study of clinical, pathological, and electroencephalographic features in 137 full-term babies with a long-term follow up. Pediatrics. 1970; 45.
20. Painter MJ, Scher MS, Stein AD, Armatti S, Wang Z, Gardiner JC, et al. Phenobarbital compared with phenytoin for the treatment of neonatal seizures. N Engl J Med 1999; 341:485-9. [CrossRef]

21. El-Dib M, Soul JS. The use of phenobarbital and other anti-seizure drugs in newborns Semin Fetal Neonatal Med 2017; 22: 321-7.

22. Han JY, Moon CJ, Youn YA, Sung IK, Lee IG. Efficacy of levetiracetam for neonatal seizures in preterm infants. BMC Pediatr 2018; 18: 131. [CrossRef] 